\title{
The Characteristics of Blind and Visually Impaired People Evacuation in Case of Fire
}

\author{
DMITRY A SAMOSHIN, and ROMAN N ISTRATOV \\ Academy of State Fire Service of Russia \\ 4, Borisa Galushkina Street \\ Moscow, 129366, Russia
}

\begin{abstract}
This work presents the results of a survey aimed at identification of key issues concerning the provision of fire safety of people with visual impairments). The questionnaires were passed to All Russian Association of the Blind and distributed by them to places of labour application (plant for the production of electrical appliances) of this group of disabled people. A methodology for field observations of flows movement consisting of blind and visually impaired people has been developed based on the results of this survey. This methodology takes into account not only the type of route (horizontal, inclined or door), but also the level of people awareness about the features on this route. Statistical processing of data and the regularities identified on its basis enabled us to describe the parameters of flows movement. It was found that the familiarity with egress route is a key factor for the safety of visually impaired people: if familiar route is blocked and number of abled-body staff is insufficient, evacuation would be failed.
\end{abstract}

KEYWORDS: blind, visually impaired, survey, movement in a flow

\section{INTRODUCTION}

According to the World Health Organization, there are about 39 million blind and 285 million visually impaired people worldwide. All Russian Association of the Blind gives the number of visually impaired people in Russia as 218 thousand people and 103 thousand of them are blind $(0.15 \%$ and $0.07 \%$ from total population of Russia consequently). In this connection almost all countries of the world implement the measures aimed at improving the environment for people with disabilities of various categories. For example, in Russia there is a program named "Accessible Environment", the goal of which is to provide conditions for equal access of disabled people to buildings and structures, objects of transport, information and communication, as well as to various services. However, the reaction of people to the changes has not been researched deep enough. Therefore, it is impossible to assess the actual effectiveness of both implemented and planned measures. Clarification of various aspects of this issue was made in the studies of authors conducted in 2012 through a survey of members of the All Russian Association of the Blind [1].

One of the ways of improving social activity, overcoming self-isolation and increasing social cohesion of people with disabilities is creation of possibilities for application of their work. Enterprises, which employ only blind and visually impaired people, operate under the auspices of the All Russia Association of the Blind, which requires consideration of the problems of their fire safety maintenance. As is known, one of the most effective measures made to ensure the safety of people in case of fire is their evacuation. Taking into consideration that people with visual impairments prefer to use traditional ways of movement, evacuation of other building occupants would actually take place along the same route, which may lead to the high density of the flows of people. Currently, studies of free movement parameters (i.e., excluding the impact of the flow density) of visually impaired people have been conducted [2], but data on flow movement of blind and visually impaired people has not been published. In order to establish the connections between movement parameters of the flows of people the authors have conducted field studies at enterprises with major functional contingent of blind and visually impaired people. Statistical processing of data and the regularities identified on its basis allowed to describe the parameters of movement in a flow of this category of people with disabilities. 


\section{SURVEY OF MEMBERS OF THE ALL RUSSIAN ASSOCIATION OF THE BLIND}

The survey was undertaken by means of questionnaires that were distributed by All Russian Association of the Blind to the supervising industrial plants in the different cities of Russia, where visually impaired people were employed. Questionnaires were returned by 201 visually impaired persons $(17.3 \%$ of them are completely blind). Among them, $68.2 \%$ of people were over 40 years, the percentage of women was $49.8 \%$, men $-50.2 \%$. In accordance with the Russian medical legislation, all people with disabilities are divided into three groups depending on their functional system of the body (the most severe problems relate to group I, the least to group III). Among the surveyed people with disabilities there were $35.4 \%$ from group I, $44.1 \%$ from group II, and $20.5 \%$ from III.

The increased vulnerability of these groups of people should predetermine the demanding attitude to their workplace fire training. The received data on the training of surveyed people with disabilities is given in Table 1.

Table 1. Fire training of visually impaired people.

\begin{tabular}{|l|l|c|}
\hline \multicolumn{1}{|c|}{ Survey question } & \multicolumn{1}{|c|}{ Variants } & \% of surveyed \\
\hline \multirow{2}{*}{$\begin{array}{l}\text { Are you familiar with the general } \\
\text { requirements of fire safety and rules } \\
\text { of behavior in case of fire? }\end{array}$} & $\begin{array}{l}\text { Yes, but would prefer to undergo } \\
\text { additional training }\end{array}$ & 83.5 \\
\cline { 2 - 3 } & No & 4.5 \\
\hline $\begin{array}{l}\text { Have anyone conducted with you any } \\
\text { special classes on fire safety } \\
\text { concerning your impaired body } \\
\text { functions? }\end{array}$ & $\begin{array}{l}\text { Yes, but would prefer to undergo } \\
\text { additional training }\end{array}$ & 12.0 \\
\cline { 2 - 3 } $\begin{array}{l}\text { Have you participated in the } \\
\text { evacuation drills? }\end{array}$ & Yes & 72.9 \\
\cline { 2 - 4 } & No & 6.6 \\
\hline
\end{tabular}

Table 1 data show the overall good level of fire training of blind and visually impaired people. This is due to the fact that visually impaired people undergo special rehabilitation courses, which include the basics of fire safety. Moreover, the survey was conducted at operating enterprises and safety management includes fire safety issues.

The vast majority of surveyed people with disabilities consider regular fire training to be a basis to ensure their safety in case of fire and point out the need to conduct regular classes and exercises with them. However, about $20 \%$ of them indicated that they further needed both theoretical and practical training. It is interesting to note that many people with disabilities pointed out the need for training of surrounding people on interaction with people with disabilities, especially in case of emergency. For example, only half of the surveyed noted responsive attitude of the staff and other people to their complications. Only $20.6 \%$ of respondents experienced special service at airports, hotels, etc.

In general, visually impaired people rely on the conscientious performance of duties by the officials to a greater extent than sighted people, because this, in their opinion, would help prevent the fire and largely eliminate its consequences. There is a great hope of people with disabilities on technical means of automatic fire extinguishing systems. A number of respondents associate their security with automatic fire extinguishing systems that allow to locate and extinguish the fire timely. At the same time, the answers of blind and visually impaired people suggest that the warning and evacuation system does not take into account their peculiarities and does not allow to fully ensure the fire warning and control the process of evacuation in case of fire.

Answers of blind and visually impaired people about the first actions in case of fire have shown that many of them will wait for the foreman (usually, a sighted person or a person with minor visual disturbances), and leave the building following his or her lead. However, despite the body malfunctions, there are a significant number of people among those who are willing to take actions to ensure the fire safety not only for themselves but also for surrounding people, Table 2 . 
Table 2. Possible actions of visually impaired people in case of fire.

\begin{tabular}{|l|l|c|}
\hline \multicolumn{1}{|c|}{ Actions in case of fire } & \multicolumn{1}{|c|}{ Variants } & \% of surveyed \\
\hline \multirow{3}{*}{ Extinguish a fire } & Yes & 29.5 \\
\cline { 2 - 3 } & Probably yes & 20.2 \\
\cline { 2 - 3 } & No & 50.3 \\
\hline \multirow{3}{*}{ Call the fire department } & Yes & 78.2 \\
\cline { 2 - 3 } & Probably yes & 13.2 \\
\cline { 2 - 3 } & No & 8.6 \\
\hline \multirow{3}{*}{ Turn on a warning system } & Yes & 25.8 \\
\cline { 2 - 3 } & Probably yes & 21.3 \\
\cline { 2 - 3 } & No & 52.8 \\
\hline \multirow{3}{*}{ Organize the evacuation } & Yes & 33.5 \\
\cline { 2 - 3 } & Probably yes & 19.0 \\
\cline { 2 - 3 } & No & 47.5 \\
\hline
\end{tabular}

The data in Table 2 show that, in general, actions of blind and visually impaired people will be aimed at notification of the fire department. However, people with severe visual impairments are ready to take an active part in fighting a fire: turn on a warning system, organize the evacuation and even extinguish a fire.

Despite the apparent vulnerability of blind and visually impaired people, in some situations in case of fire they have an advantage over sighted people. The most common calculation criterion of "loss of sight" does not have a significant impact on visually impaired people. The head of rehabilitation department of production enterprise "Kuntcevo-Electro" Ltd (who is completely blind) gave the following example. There was a fire on the floor of the apartment building where he lives. He was the only person of all people living on the floor who was able to navigate and find an evacuation route in conditions of high-density smoke (while protecting his respiratory system).

Most people with visual disabilities clearly understand their vulnerability in case of fire and it could be seen through the answers on the question about their expected actions in case of fire: "I'll be confused" or "I will wait for help". Moreover, the presence of disability in some cases of emergency even causes the feeling of doom, which respondents describe in questionnaire in the following expressions: "will think about my children" and "will pray".

In general, the number of people who are prone to active actions is directly related to the disability group: the number of such people for group I is minimal, for group III - maximal.

The conducted study examined the attitude of surveyed people to fire-safes zone and the possibility of evacuation (rescue) of people with disabilities with the help of specially protected elevators. A list of questions aiming at clarifying this situation has been created. The results of this survey are shown in Table 3.

Table 3. Trends in the use of protected elevators and security zones

\begin{tabular}{|l|l|c|}
\hline \multicolumn{1}{|c|}{ Survey question } & \multicolumn{1}{|c|}{ Variants } & \% of surveyed \\
\hline Use of protected elevator for evacuating & Yes & 37.3 \\
& No & 32.1 \\
& As a last resort & 30.6 \\
\hline Evacuation to a fire-safe zone & Yes & 36.9 \\
& No & 29.7 \\
& As a last resort & 33.4 \\
\hline
\end{tabular}

The data of Table 3 show a high degree of reluctance to use the protected elevators and fire-safe zones inside the building. This is well correlated to the data of recent study of McConnel and Boyce [9] - up to one third of questionnaired people with reduced mobility stated that they would not use refuge area in case of fire. Considering results of the given study, authors see two reasons of such answers. First one is an ageold prohibition of use of elevators for evacuation in case of fire. Today, for example, a number of buildings have the warning not to use elevators in case of fire. This is justified since the elevator halls are not 
protected with fire barriers and air overpressure, so, because of the natural draft induced by the force of gravity, elevator shafts become the channels of intensive spread of dangerous fire factors. People are not aware of the fact that modern elevators can be produced with the same level of fire protection as smokeresistant stairwells. Second, the source of this reluctance may be the actual inaccessibility of fire-safe zones to people with disabilities, if they are organized only on certain floors of buildings. Identification of reasons of reluctance to use elevators for evacuation in case of fire and fire-safe zones for temporary protection determines the methods to eliminate it. This, on the one hand, is the improvement of fire training of people with disabilities that expands their understanding of provision of fire safety; on the other hand, it is the monitoring of secure functioning of technical systems of fire safety.

Respondents were also asked to express their views about necessary, in their opinion, methods and means to improve their fire safety (so called "open question"). Analysis of the answers revealed a remarkable unanimity - "it is hard to navigate in the building" and vast majority of people with disabilities stated that they require aural beacons for self-orientation in building - devices that relay a certain sound that indicates, for example, an emergency exit, or, if more broadly, that allow to establish the space interrelation between man and the internal layout of the building. Moreover, the studies conducted in our country have shown high effectiveness of trainings for blind people, even children, on orientation in space with the help of sound-signaling typhlo-technical (Gr. Typhlös - blind) devices [3].

The lack of tactile and color marking deteriorates the maneuvering, forces people to move to the touch, leading to the reduction of overall speed. The greatest difficulties in movement are caused by doorways (glass doors and lack of contrast color indication of exits) and staircases due to the lack of tactile and contrast indicators of the first and last steps. Surveyed people have a serious concern about the condition of evacuation routes and availability of opened emergency exits due to the inability to quickly change the evacuation route and use another emergency exit, in comparison with the healthy person. Inability to use a known evacuation route and greater complexity of orientation on unknown territory lead to the fact that some of the respondents will not even try to get out of the building. For example, one respondent stated: "if the exit is blocked, I'll jump out of the window".

Therefore, the next group of questions was aimed at clarifying the peculiarities of orientation and movement of people in the building. The survey of visually impaired people showed that, first of all, the familiarity with the peculiarities of the route is the factor that determines their ability to use this route. The data in Table 4 shows the results of the survey of visually impaired people on this matter.

Table 4. Assessment of the possibility of evacuation depending on familiarity with an evacuation route for visually impaired people

\begin{tabular}{|l|c|c|}
\hline \multicolumn{1}{|c|}{ Familiarity with an evacuation route } & Variant & \% of surveyed \\
\hline \multirow{2}{*}{ Are you able to evacuate yourself using a familiar route } & Yes & $81.3 \%$ \\
\cline { 2 - 3 } & No & $18.7 \%$ \\
\hline Are you able to evacuate yourself using an unfamiliar route & Yes & $39.7 \%$ \\
\cline { 2 - 3 } & No & $60.3 \%$ \\
\hline
\end{tabular}

The data in Table 4 shows that $18.7 \%$ of surveyed people are not able to self-evacuate even using a familiar route, but in the case of blocking it with fire, the number of people increases by almost 3 times and $60.3 \%$ of respondents stated that they are not able to evacuate without assistance. It should be noted that the familiarity with the route influences the movement in the city: $80.5 \%$ confidently move unaccompanied using familiar routes, while only $34.7 \%$ for unfamiliar ones.

Interviews with blind and visually impaired people showed that in order to learn a new movement (evacuation) route, they need to go through it 2-3 times together with the sighted person, then once on their own, but under control, and only after that they are able to use the considered route section independently.

Of course, the fire safety of visually impaired people depends on the level of fire training, automatic firefighting equipment, space planning and design solutions of emergency routes and exits, including their tactile and color-marking indication and requires further work on the improvement of these measures. However, in case of fire blind and visually impaired people will move to the exits from the building, which leads to the need to study the parameters of their movement through different types of paths in order to assess the possibility of various engineering solutions aimed at their security. 


\section{THE STUDY OF INDIVIDUAL AND FLOW MOVEMENT OF VISUALLY IMPAIRED PEOPLE}

Experiments and field observations of movement of groups of people through different types of evacuation routes were conducted at two plants of the All Russia Association of the Blind in order to determine the dependencies between the parameters of the movement of human flows of blind and visually impaired people. A total of 51 people (with different level of visual impairments, but without signed persons) took part in the study, arranged as an experiment. A part of egress route was selected (30-50 meters for corridor, 2 floors for stairs up and down and several door openings) and volunteers were asked to move as quickly as possible, considering fire situation in a plant. In all cases two experimental scenarios were arranged: movement along familiar path (i.e. well-know route used in daily routine) and unfamiliar path with unknown characteristics. In order to determine the dependences between the parameters of the movement of the flows of people, experiments of flow movement through various sections of the path using video equipment were conducted. Before the video record was performed, a scale grid with $1 \times 1 \mathrm{~m}$ cells had been built and installed at the test site in order to record the parameters of the movement of people through sections of communication paths (horizontal section, stairs down and up). Then a test frame that records the geometric dimensions of the section and a size grid with regard to the perspective distortions was constructed. After that the grid was removed. It should be noted that modern digital cameras "Spy" were used for the first time during the field observations, in contrast to the ones previously conducted. Their compact size (including small weight) and the possibility of placement virtually anywhere in the room ease the organization of observations, do not attract attention of the people observed or distort their behavior.

The analysis of video tapes and the creation of a statistical sample of received data were made after the experiment. After the video showed a frame with a size grid, the video was stopped and outlines of the grid were drawn on the computer display with a marker pen, Fig. 1. Viewing of the footage continued with a scale grid on the display.
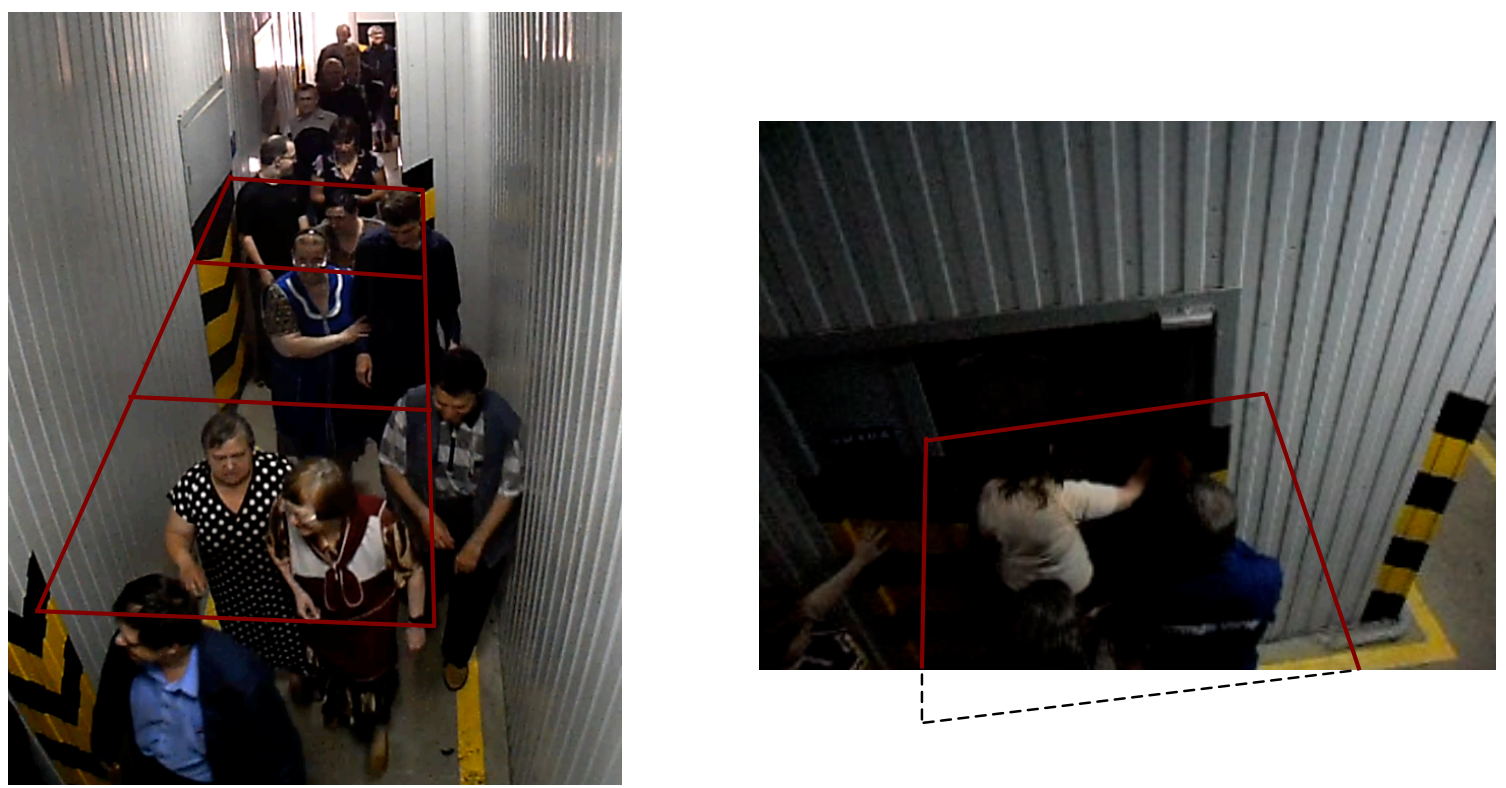

Fig. 1. An example video tape processing (overlay of the scale grid of $1 \mathrm{x} 1 \mathrm{~m}$ ): a) horizontal plane; b) door;

Once a person gets to the boundary of the first square of the grid, the number of people in the cell in front of him is counted, and thus the density of the flow $D_{i}$, expressed in persons $/ \mathrm{m}^{2}$, is calculated. With this density the observed person travels a distance of $\Delta l$ in a certain period of time $\Delta t$. This time is calculated as a relation between measured number of frames per second $(f p s)$ and number of frames per second which is a video tape property $\left(f p s^{\prime}\right)$. Thus travel speed $V_{D}$ is calculated:

$V_{D}=\Delta l / \Delta t, m /$ minutes, where $\Delta t=\frac{f p s^{\prime}}{f p s} \times 60$, minutes 
This process is continued until the observed person leaves the observation zone. Likewise, the movement of following people selected for observation is traced.

This is a general method of determining the values of movement speed of people in the flow through the linear sections of the communication path. The movement speed through the doorway is impossible to measure in the same way since the length of the path section in the doorway is close to 0 . Therefore, while moving through the doorway, the number of people $N$ passing through it over a certain time interval $\Delta t$ was counted. The $\Delta t$ value was determined by the duration of existence of the flow of certain density $\mathrm{D}_{\mathrm{i}}$ in front of the doorway. If $N$ values are measured, then movement intensity $\left(q_{D}\right)$ through the doorway of $b(\mathrm{~m})$ wide at flow density $D_{i}$ that is observed in front of it over the time interval $\Delta t$ might be calculated:

$q_{D}=N / b \Delta t$, persons $/(\mathrm{m} \cdot \mathrm{min})$

and then the speed $V_{D}$ of crossing the doorway at the density $D_{i}$ :

$V_{D}=q_{D} / D_{i}, \mathrm{~m} / \mathrm{min}$

Statistical analysis permitted to reveal a relation between travel speed and flow density and empirical curves were plotted. However, it is known that the mathematical formula that we fit to approximate empirical data only then gets a real value when it is adequate to the inner relations of the phenomena. These inner relations were found in the 80 s of last century [4,5] and are being used for more than 30 years in Russian Building Codes. Theoretical relations were constructed based on the empirical data in the form of the following law:

$V_{D}=V_{0}\left(1-a \ln D / D_{0}\right)$ if $D \geq D_{0}$

In this formula: $V_{D}$ is a speed of flow movement; $V_{0}$ is the random variable of speed of free movement of people in the flow that depends on physical and psychological state of people; $D_{0}$ is the threshold value of the density i.e. density does not affect the speed of movement of people; $a$ is the coefficient of people's adaptation to changes in the flow density while; $D$ is the value of density of the flow of people. It should be noted, that this type of dependence is true not only for healthy people and, as was shown above, visually impaired people, but also for description of the parameters of movement of flows of people with affection of musculoskeletal system [6], as well as elderly (infirm) people [7] and pre-school children [8]. Statistical analysis of the movement parameters of blind and visually impaired people showed a significant difference between the series received while using familiar and unfamiliar routes. A classification indicator that reflects the level of familiarity with evacuation route was introduced on this basis in order to assess the movement parameters of visually impaired people, Tab. 5, Fig. 2. Given on the Fig. 2 relations are within $95 \%$ confidence limits against a theoretical profile of $\mathrm{V}=\mathrm{f}(\mathrm{D})$. Correlation coefficients of over 0.95 indicate good functional relationships and confirm the validity of the established function.

Table 5. The parameters of the flow consisting of blind and visually impaired people

\begin{tabular}{|l|l||c|c|c|c|}
\hline \multirow{2}{*}{ Mobility group } & \multirow{2}{*}{ Parameters } & \multicolumn{4}{c|}{ Type of route } \\
\cline { 3 - 6 } & & horizontal & doorway & stairs up & stairs down \\
\hline \hline \multirow{3}{*}{ Familiar route } & $V_{0, j}, \mathrm{~m} / \mathrm{ss}$ & 0.83 & 0.54 & 0.67 & 0.57 \\
& $D_{0, j}$, people $/ \mathrm{m}^{2}$ & 1.03 & 0.20 & 0.97 & 0.82 \\
& $a_{j}$ & 0.4919 & 1.1898 & 0.5188 & 0.3869 \\
\hline \multirow{3}{*}{ Unfamiliar route } & $V_{0, j}, \mathrm{~m} / \mathrm{s}$. & 0.44 & 0.36 & 0.36 & 0.30 \\
& $D_{0, j}$, people $/ \mathrm{m}^{2}$ & 1.03 & 0.20 & 0.97 & 0.82 \\
& $a_{j}$ & 0.4919 & 1.1898 & 0.5188 & 0.3869 \\
\hline
\end{tabular}




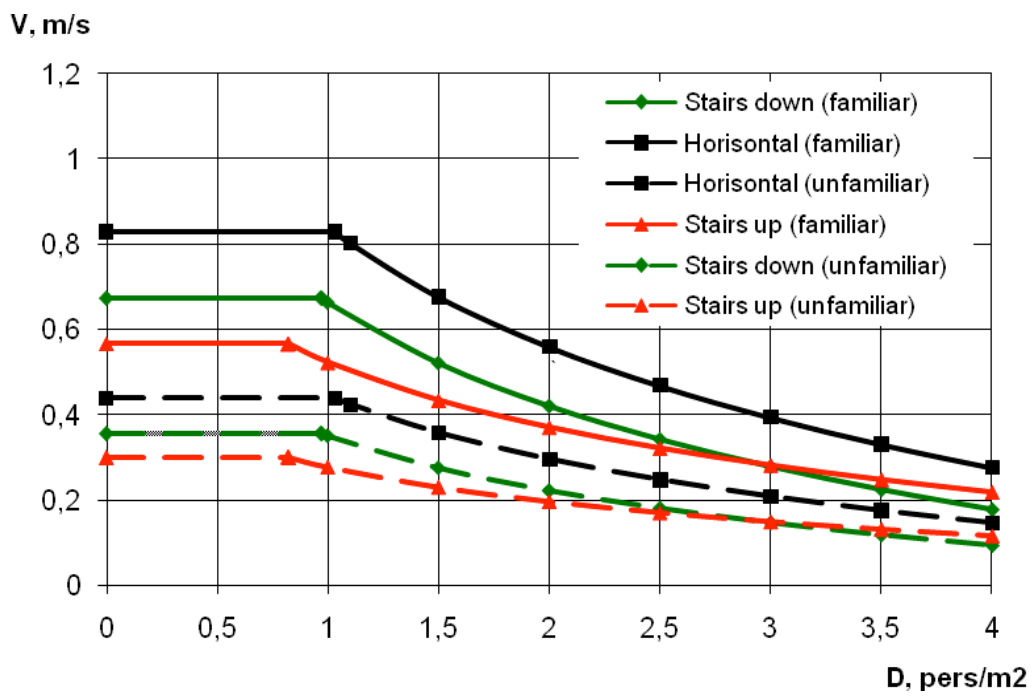

Fig. 2a. The relation between travel velocity and density of flow consisting of blind and visually impaired people

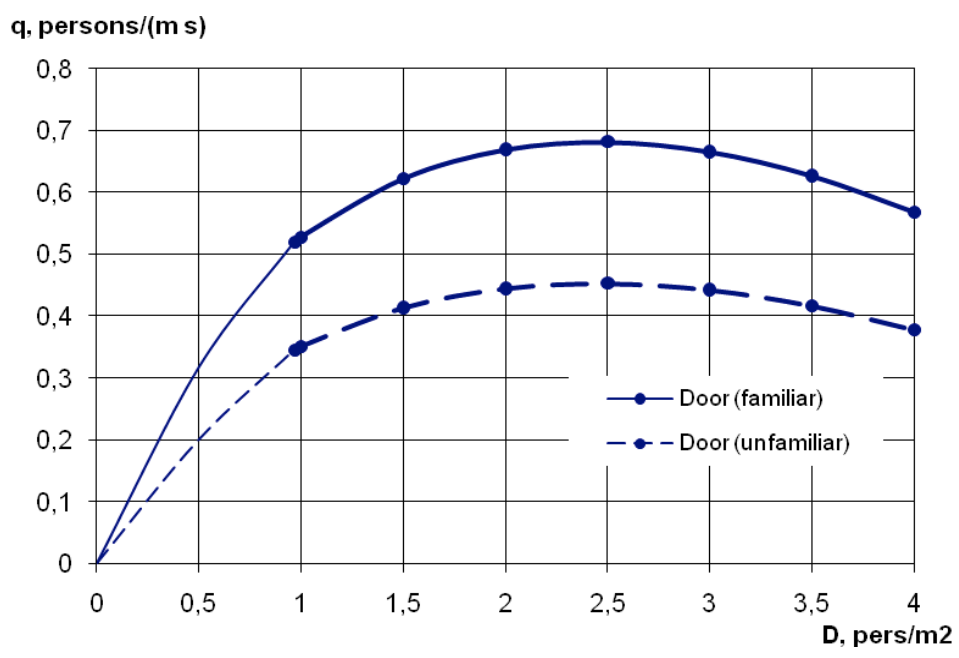

Fig. 2b. The relation between intensity of movement (sometimes called "specific flow") and density of flow consisting of blind and visually impaired people

The data shown in Fig. 2a gives us grounds to point out several special features. Firstly, there is a higher value of threshold density compared with healthy people [6,7]. Secondly, there is a relatively small difference in values of the parameters characterizing the movement of people through horizontal and inclined path and especially between the movement up and down stairs. This is due to complexity of a movement task for disabled people of this group, and, as a consequence, the minor influence of the irritant surrounding people. However, despite the gradual drop in speed, movement speed becomes very low with the flow density of more than 2 people $/ \mathrm{m}^{2}$ (about $0.25 \mathrm{~m} / \mathrm{s}$ for an unfamiliar path and about $0.42 \mathrm{~m} / \mathrm{s}$ for a familiar one). The density of the human flow 2.5 persons $/ \mathrm{m}^{2}$ in front of door, Fig. $2 \mathrm{~b}$, gives maximum intensity of movement $(0.68$ persons $/(\mathrm{m} \mathrm{s})$ or about 41 persons $/(\mathrm{m}$ minutes $)$. This indicates the need to develop and implement a set of measures excluding the constrained movement of people in a flow with density higher than 2.5 persons $/ \mathrm{m}^{2}$.

It should be noted that the given values for an unfamiliar path were received during a controlled experiment - participants of the experiment were partly familiar with the "unfamiliar" section of the path 
(measurements were carried at the plant's territory where they work), and moreover, of course they knew that they are followed by people who eliminate the risk of injury.

Despite the recent upsurge of interest in the interaction between people during the movement in the flow that is primarily caused by capabilities of modern computers, there is a lack of actual material published even on the issue of the movement of people without impaired body functions. In this regard, the authors have tried to identify and describe some regularity of the features of individual movement of people. The analysis found that in some cases, the movement of visually impaired people occurs quicker if they move in the dense flow, and the movement of individual persons, conversely, can occur slower. For example, Fig. 3 shows a situation where a visually impaired person needs to be directed in order to successfully reach and pass the doorway.

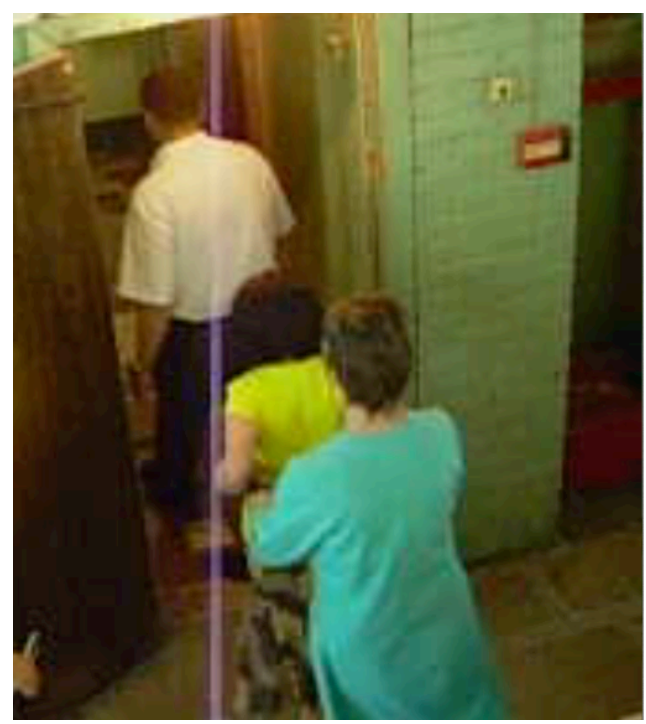

Fig. 3. Passing of the narrow doorway by a person with strong vision loss: surrounding people direct the disabled person from behind.

It was also indentified that if healthy people try to avoid physical contact with the enclosing structures (the concept of "effective width" of the section of the path was introduced for this purpose), such contact is necessary for the movement of visually impaired people, Fig. 4a. There is a higher probability of movement in groups - more than $50 \%$ of people with disabilities evacuated in this way. People in a group hold hands very often, Fig. $4 \mathrm{~b}$ and $4 \mathrm{c}$, which is typical both for mixed groups as well as for the groups consisting only of men.
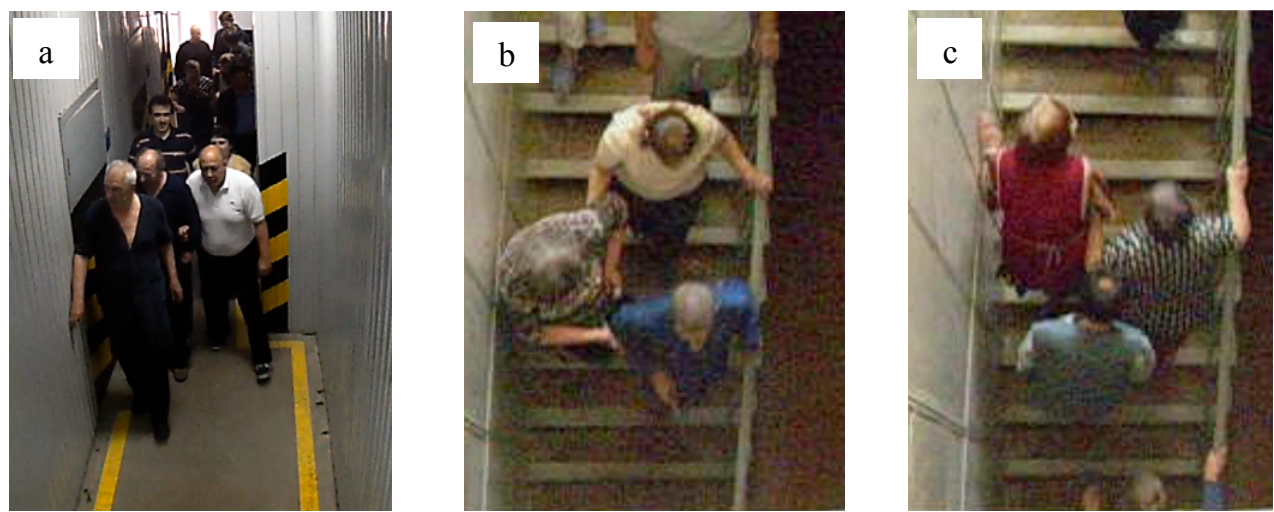

Fig. 4. Tactile contact with enclosing structures (walls and railings) and distinct group movement of visually impaired and blind people. 
Thus, the conducted study of the movement of the flows of blind and visually impaired people allowed to form statistical database and set the values that describe the communication regularities between the parameters of flows depending on the type of path, characteristics of pedestrian and movement conditions.

\section{CONCLUSION}

International legislation (such as the Convention on the Rights of Persons with Disabilities [10]), as well as legislation of many countries establish the need to provide equal opportunities for all people. However, for example, the improvement of availability of infrastructure leads to the increase in the number of people with disabilities in such buildings, which produces high requirements to provision of their safety. But at present, not all of the required tasks to achieve this purpose are solved.

The given work describes the results of a complex study (using surveys and video observation) of issues of provision of fire safety for blind and visually impaired people. Surveys allowed to identify the attitude of visually impaired people to their fire training, actions in case of fire, relation to the rescue with the help of fire-safe zones and protected elevators. An extremely important fact revealed by the survey is the influence of familiarity with an evacuation route on the possibility of using it in case of fire, which was taken into account during the development of research methodology of the parameters of movement of flows of visually impaired people.

The experimental and field observations of the movement of the flows of people in buildings with mass stay of blind and visually impaired people helped to create statistical database that characterizes the movement of flows through horizontal sections of the path, up and down the stairs depending on familiarity of evacuation route. Values of quantities that describe the regularities between the parameters of flow, consisting of visually impaired people were identified. The study of individual movement of these people in general flow and further analysis of the received results revealed a number of regularities of their movement.

\section{ACKNOWLEDGEMENT}

The authors are the employees of the educational and research centre on "Fire safety in construction" and they would like to thank their head, doctor of technical science, prof. B.B. Serkov for continued support of this research area. The authors are grateful to the head of scientific school of "Theory of the movement of flows of people" led by doctor of technical science, prof. V. V. Kholshchevnikov, for his advice on scientific and practical implementation of work. In addition, the authors are grateful to the management of the All Russia Association of the Blind and all the people who voluntarily participated in the experiments.

\section{REFERENCES}

[1] Kholshevnikov VV., Samoshin D.A., Istratov R.N., (2013) Study of the problems of ensuring fire safety of persons with impaired vision, hearing and locomotor system. Fire and Explosion Safety 22/3: 48-56 (In Russian).

[2] Sorensen J., Dederich A. "Evacuation characteristics of blind and visual impaired people. Walking speeds on horizontal plane and descending stairs". Proceedings of 5th International Symposium "Human Behaviour In Fire". Cambridge. Uk, 2012, pp. 304-314.

[3] Tinovskii R.N. The education of blind children orienteering in the sound field with the help of technical means. The author's abstract of the dissertation of candidate of pedagogical sciences. Moscow, 1987 (In Russian).

[4] Kholshevnikov VV. Human flows in buildings, structures and on their adjoining territories. Doctor of science thesis. Moscow, 1983 (In Russian).

[5] Kholshevnikov V.V., Shields T.J., Boyce K.E, Samoshin D.A., (2008) Recent developments in pedestrian flow theory and research in Russia. Fire Safety Journal 43: 108-118.

[6] Samoshin D.A., Istratov R.N. "The Parameters of Pedestrian Flows in Hospital During Fire Evacuation". Proceedings of 13th International Conference and Exhibition on Fire Science and Engineering “Interflam 2013” Royal Holloway College, Nr Windsor, UK, 24-26 June 2013 (accepted for publication). 
[7] Kholshchevnikov V.V., Samoshin D.A, Istratov R.N. "The problems of elderly people safe evacuation from senior citizen heath care buildings in case of fire". Proceedings of 5th International Symposium "Human Behaviour In Fire". Cambridge. Uk, 2012, pp. 587-593.

[8] Kholshchevnikov V.V., Samoshin D.A., Parfyonenko A.P., Belosokhov I.R., (2012) Study of Children Evacuation from Pre-school Education Institutions. Fire and Materials 36: 349-366.

[9] McConnell, N. C. and Boyce, K. E. (2013) Refuge areas and vertical evacuation of multistorey buildings: the end users' perspectives. Fire and Materials Journal, doi: 10.1002/fam.2205

[10] UN General Assembly, Convention on the Rights of Persons with Disabilities : resolution / adopted by the General Assembly, 24 January 2007, A/RES/61/106. 